\title{
Understanding violent extremism in the 21st century: the (re)emerging role of relative deprivation Jonas R Kunst ${ }^{1,2,3}$ and Milan Obaidi ${ }^{2,3}$
}

Recently, the world has experienced a wave of violent protest, and in particular Islamist and right-wing extremism have become increasing challenges for many societies. We argue that especially the experience of relative deprivation, that is the perception that oneself or one's group is undeservingly worse off than others, can explain various, contemporary forms of violent extremism, including (a) low-power groups' violent attempts to challenge the unequal status quo, (b) high-power groups' violent defense of their privileged position, and sometimes even (c) people's violent attempt to help out-groups in need. In light of recent research and growing social inequalities, we expect relative deprivation to be a key factor driving violent extremism across cultures and contexts in the 21st century.

\footnotetext{
Addresses

${ }^{1}$ Department of Psychology, University of Oslo, Norway

${ }^{2}$ Center for Research on Extremism, University of Oslo, Norway
}

Corresponding authors:

Kunst, Jonas R (j.r.kunst@psykologi.uio.no), Obaidi,

Milan (milan.obaidi@c-rex.uio.no)

${ }^{3}$ Shared first authors.

\section{Current Opinion in Psychology 2020, 35:55-59}

This review comes from a themed issue on Social change (rallies, riots and revolutions) (2020)

Edited by Séamus A Power

For a complete overview see the Issue and the Editorial

Available online 3rd April 2020

https://doi.org/10.1016/j.copsyc.2020.03.010

2352-250X/C 2020 The Author(s). Published by Elsevier Ltd. This is an open access article under the CC BY license (http://creativecommons. org/licenses/by/4.0/).

"They are the kings, and we are the slaves. Enough."

Suzy Barakat, protester, Beirut, 2019 [1]

From 2017 to 2020, the world witnessed a wave of violent protests, ranging from Bolivia to Hong Kong, France, Spain, Venezuela, Iraq, Lebanon, and Chile, to name just a few. At the same time, many societies have faced challenges related to individuals and groups engaged in terrorist and other types of violent extremist activities. Most prominent examples include the increase of rightwing extremism in the West and the rise of ISIS in the Middle East [2]. In this review, we aim to demonstrate that the experience of relative deprivation is a motive often shared by individuals and groups engaged in such contemporary forms of violent extremism. Consequently, we argue that, due to rising social inequalities and corresponding power asymmetries intra- and internationally, the experience of relative deprivation is likely to become one of the key factors driving violent extremism across groups, cultures and contexts in the 21 st century.

\section{Relative deprivation and collective action}

A central way by which humans obtain information about themselves and their social standing in society is through social comparisons [3], and relative deprivation describes a negative evaluation resulting from this [4-7]. Specifically, relative deprivation involves the perception that oneself or one's group does not receive valued resources, goals, ways or standards of living, which others possess and one feels rightfully entitled to $\left[8^{\bullet}\right]$.

Relative deprivation has for long time been used to explain why people engage in political and social protest [for a review, see Ref. [6]]. Underlining its subjective nature, relative deprivation can trigger collective action even for people who are not personally and directly affected by injustice but who still perceive themselves to be victims of it [e.g. [9]]. Such subjective perceptions predict collective mobilization [10], and often are stronger predictors of non-normative forms of protest than more objective types of deprivation [11]. Subjective feelings of relative deprivation do not necessarily mirror objective conditions [see Refs. 12-15], although they likely are informed by the latter [16]. Interestingly, sometimes both objective and subjective deprivation interactively predict protest. For instance, as referred to as the 'deprivationprotest paradox,' people may protest especially if their own negative experiences of deprivation do not fit macrolevel positive economic outlooks in their social environments $\left[8^{\bullet}, 17\right]$. Additional important factors here include people's understandings of the past (e.g. collective remembering) and visions of the future [18 ${ }^{\bullet \bullet}$.

It is important to emphasize that relative deprivation does not always lead to violent extremism or other forms of nonnormative behavior [see Refs. $\left[8^{\bullet}, 19\right]$. That is, the cognitive component of relative deprivation (i.e. the mere realization that one receives less than one feels rightfully entitled to) often has less influence on non-normative collective action than its affective components [i.e. perceived illegitimacy, feelings of anger or injustice; $\left.20^{\bullet \bullet}, 21-24\right]$. In other words, 
people may engage in violent extremisms to counter feelings of their own and especially their group's lost economic, social and psychological significance $\left[25,26^{\bullet \bullet}, 27\right]$.

Most research so far has investigated the role of relative deprivation for normative forms of collective action. Whereas many theories and models suggest that relative deprivation also plays a key role for extremism [28,29], little research has directly investigated this relationship, and especially applications to current forms of extremism are missing. However, as we aim to demonstrate, in particular research from the recent years supports the central role of relative deprivation for understanding contemporary types of extremism among low-power and high-power groups alike.

\section{Extremism among low-power groups: fighting against perceived injustice}

Attempts to explain the rising proliferation of extremism among low-power groups (and Muslims in the West and Middle East specifically) have led many to suggest a causal relationship between extremism and objective deprivation [e.g. poverty, low educational attainment, or lack of political influence; [30,31]. However, evidence for this association seems to be lacking [see, e.g. 32-34], although exceptions exist [e.g. 35,36]. In fact, Muslim individuals enrolled in higher education and high earners are sometimes more likely to support and sympathize with violent protest and acts of terrorism [37,38], and those born in the West tend to be more inclined to endorse violence than those born in conflict areas $\left[20^{\circ \bullet}\right]$. This suggests that, rather than actual deprivation, what matters in particular may be minority-group members' subjective experience of it. Indeed, a recent study conducted with Muslim youth in the Netherlands suggested that perceptions of relative deprivation and consequent violent intentions may stem in parts from intergroup experiences their parents teach them about [39].

Relative deprivation can powerfully explain large-scale domestic riots by low-power groups such as those following the Arab spring. Using a creative operationalization of relative deprivation by measuring the negative change in national-level feelings of happiness from 2009 to 2010, Korotayev and Shishkina $\left[40^{\circ}\right]$ showed that relative deprivation was related to more sociopolitical destabilization across a range of Arab countries. At the micro-level, a relative deprivation perspective also seems vital in explaining extremist violent movements such as Jihadism. For instance, in a study conducted with Muslims in the Netherlands, perceived group deprivation (but not individual deprivation) predicted more support for violence [41] [also see Ref. 42]. Moreover, a recent study suggested that this relationship further depends on participants' immigrant generation. Second-generation Muslim immigrants from 20 Western countries endorsed violence more than first-generation Muslim immigrants and non-Muslims did [21]. Importantly, their elevated anger and violent inclinations were explained primarily by the perception of being stigmatized and having low status in society. Hence, the unfavorable comparison of their own group's social standing to that of the native/ autochthonous population (e.g. the advantaged, highpower group) may lead Muslims to show more violent extremism - arguably a 'counter-dominance' attempt to attenuate the prevailing power asymmetry [cf. 43].

Studies from the Middle East provide convergent results. For instance, the more Christians and Muslims in Syria and Lebanon perceived domination and exploitation by the U.S., the more they supported violent action against American targets [44]. Similarly, the more unjust Muslims living in Afghanistan, Pakistan and Western societies experienced Western military and foreign policy, the more violent behavioral intentions they showed [22]. Importantly, whereas relative deprivation may drive extremist violence within one cultural sphere, perceptions of mistreatment endured by group members in other parts of the world may also lead to what has been referred to as 'victimization-by-proxy' $\left[20^{\circ \bullet}\right]$. For instance, when Muslims in the West perceive that religious peers in other geographical areas (e.g. the Middle East) experience deprivation, this can have the same effects on violent behavioral intentions as experiencing deprivation oneself. This finding, hence, underlines the need to understand the interconnectedness of social systems in various parts of the world when investigating the effect of relative deprivation on violent extremism.

\section{Extremism among high-power groups: defending or challenging the status quo}

The reviewed studies confirm the role of relative deprivation among groups who have low power intra- and internationally. But what about groups with relatively high power within these social systems? Generally, in an attempt to defend their dominant status, members of high-power groups seem to show more violent extremism against out-groups when intergroup inequality is high [45-47]. Some evidence further suggests that this tendency is potentiated by the subjective experience of relative deprivation. In a study with Dutch youth, experiences of group and personal relative deprivation were both correlated with more support for right-wing extremist violence and own violent intentions [48]. Similarly, in Indonesia where Islam is the dominant religion, the more injustice Muslim majority-group members perceived against their group, the more they supported harm against other people to enforce their religious group's political influence [49]. Causal evidence for such a relationship was further obtained in a recent experimental study $\left[50^{\circ}\right]$. White U.S. Americans with a Republican affiliation were asked to recall potential experiences of relative deprivation or mundane life experiences. Participants in the relative deprivation condition showed a stronger willingness to violently persecute political out- 
groups. Interestingly, mediation analyses showed that effects on these extremist tendencies were largely mediated by people's increased closeness [i.e. identity fusion; see Ref. 51] with their political leader. In other words, the more relative deprivation people experienced, the more they fused with their political leader, which in turn made them more willing to violently fight people who this leader had identified as threats. This finding may help explain past political movements in which extreme leaders were adored and followed, and that ultimately resulted in intergroup atrocities. Moreover, the observed processes may be particularly valuable when aiming to understand intergroup relations in times of increasing populism and political authoritarianism [also see Refs. 52,53].

However, not all members of high-power groups support or engage in efforts to violently maintain the status quo, and often the opposite is true. In these cases, relative deprivation again seems to play a decisive role. For instance, perceiving that out-groups experience injustice may under certain conditions motivate normative collective action on their behalf $[9,54-56]$. But under which conditions are people willing to engage in non-normative, violent action to support groups they do not belong with? Recent work suggests that this is the case especially if the unjust treatment that an out-group is perceived to endure clashes directly with people's ideological convictions. For instance, in a series of studies [57], leftists were more likely to engage in violent protest for out-groups who tend to be seen as victims of oppression (e.g. Palestinians) than for out-groups for whom such a perception often is lacking (e.g. Kurds). Yet, experimental evidence showed that this tendency could be altered. Once the Kurds' situation was framed as an asymmetrical occupation rather than a symmetrical war (or a neutral control condition), leftists felt closer with the Kurdish people, which in turn was related to more extreme political protest on their behalf. Further analyses with a sample of aspiring foreign fighters corroborated these results. When Leftist foreign fighters experienced a moral obligation to support the Kurds in their struggle, they experienced more closeness to them and, subsequently, reported a higher likelihood to join the Kurdish People's Protection Units (YPG) in their fight against ISIS and to sacrifice their lives for the Kurdish people.

\section{Conclusion}

Perceptions of relative deprivation are powerful motivators for contemporary forms of violent extremism across cultures and contexts. They may explain the violent behavioral intentions of (a) low-power groups who aim to improve their life prospects and challenge the hierarchy, (b) high-power groups who aim to maintain the selfserving status quo, and (c) those helping out-groups whose life conditions are perceived as desperate. Overall, the predictive power of relative deprivation depends on how fairly resources, power and social status are distributed within social systems, and, importantly, how this distribution is perceived $\left[18^{\bullet \bullet}\right]$. As social inequalities internationally and within many societies around the world are increasing, if relative deprivation is not a key driver of violent extremism in the 21st century yet, it can be expected to become so over the next few decades.

\section{Conflict of interest statement}

Nothing declared.

\section{CRediT authorship contribution statement}

Jonas R Kunst: Conceptualization, Writing - original draft, Writing - review \& editing. Milan Obaidi: Conceptualization, Writing - original draft, Writing - review \& editing.

\section{References and recommended reading}

Papers of particular interest, published within the period of review, have been highlighted as:

- of special interest

$\bullet$ of outstanding interest

1. Yee V: Lebanon Roiled by Second Day of Protests as Frustration Over Chronic Corruption Boils Over. The New York Times; 2019.

2. IEP: Global Terrorism Index 2018: Measuring the Impact of Terrorism. Institute for Economics \& Peace; 2018.

3. Collins RL: For better or worse: the impact of upward social comparison on self-evaluations. Psychol Bull 1996, 119:51-69.

4. Pettigrew TF: Social evaluation theory: convergences and applications. Nebr Symp Motiv 1967, 15:241-311.

5. Pettigrew TF: Three issues in ethnicity: boundaries, deprivations, and perceptions. In Major Social Issues: $A$ Multidisciplinary View. Edited by Yinger M, Cutler R. Basic Books; 1978:25-49.

6. Smith HJ, Pettigrew TF, Pippin GM, Bialosiewicz S: Relative deprivation: a theoretical and meta-analytic review. Personal Soc Psychol Rev 2012, 16:203-232.

7. Crosby F: A model of egoistical relative deprivation. Psychol Rev 1976, 83:85-113.

8. Power SA: The deprivation-protest paradox: how the

- $\quad$ perception of unfair economic inequality leads to civic unrest. Curr Anthropol 2018, 59:765-789.

8. Power SA: The Deprivation-Protest Paradox: How the Perception of Unfair Economic Inequality Leads to Civic Unrest. Current Anthropology 2018, 59:765-789. This study aimed at explaining the observation that the Irish showed little civil unrest during times of a harsh economic recession but paradoxically did so when the economy grew steadily. Through ethnographic work and interviews, the author showed that especially when negative lived experiences do not match positive macro-level developments and accompanying narratives, this may predict protest. The paper is important as it shows how different degrees of objective and subjective relative deprivation interactively can motivate political action.

9. Tiraboschi M, Maass A: Reactions to perceived deprivation in ingroup and outgroup: a cross-cultural comparison. Eur J Soc Psychol 1998, 28:403-421.

10. Taylor DM, Moghaddam FM: Theories of Intergroup Relations: International Social Psychological Perspectives. Westport, CT: Praeger; 1994.

11. Miller DL: Introduction to Collective Behavior and Collective Action. Prospect Heights, IL: Waveland; 2000.

12. Norton MI, Ariely D: Building a better America-one wealth quintile at a time. Perspect Psychol Sci 2011, 6:9-12. 
13. Chambers JR, Swan LK, Heesacker M: Better off than we know: distorted perceptions of incomes and income inequality in America. Psychol Sci 2014, 25:613-618.

14. Duvoux N, Papuchon A: How to Measure Subjective Poverty in France - and What This Tells Us about the Anger of the Yellow Vests. EUROPP LSE Blog; 2019.

15. Kraus MW, Onyeador IN, Daumeyer NM, Rucker JM, Richeson JA: The misperception of racial economic inequality. Perspect Psychol Sci 2019, 14:899-921.

16. Jetten J, Mols F, Selvanathan HP: How economic inequality fuels the rise and persistence of the yellow vest movement. Int Rev Soc Psychol 2020, 33.

17. Power SA: Economic inequality and the rise of civic discontent deprivation and remembering in an Irish case study. In The Psychology of Radical Social Change: From Rage to Revolution. Edited by Wagoner B, Moghaddam F, Valsiner J. Cambridge University Press; 2018:29-53.

18. Power SA: Why a richer world will have more civic discontent

-• The infinity theory of social movements. Int J Qual Methods 2020. Online advance article.

In this paper, the author proposes a new theory of social movements. The particularly innovative part of the theory involves its temporal dimension that often has been neglected in previous models. Specifically, it takes into account people's perception of the past and views of the future as factors influencing experiences such as relative deprivation, which ultimatelly result in collective action.

19. van Prooijen J-W, Kuijper SMHC: A comparison of extreme religious and political ideologies: similar worldviews but different grievances. Pers Individ Dif 2020, 159:109888.

20. Obaidi M, Bergh R, Sidanius J, Thomsen L: The mistreatment of

$\bullet \quad$ my people: Victimization by proxy and behavioral intentions to commit violence among Muslims in Denmark. Political Psychol 2018, ogy39:577-593.

20. Obaidi M, Bergh R, Sidanius J, Thomsen L: The mistreatment of my people: Victimization by proxy and behavioral intentions to commit violence among Muslims in Denmark. Political Psychology 2018, 39:577-593.In this study, the authors introduced and demonstrated the phenomenon of "victimization-by-proxy." Specifically, they showed that Muslims without personal adverse experiences of war and occupation still show highly similar psychological responses to relative deprivation (e.g. perceived injustice, violent behavioral intentions) as those who have personally made these experiences. This finding is crucial as it highlights the importance of understanding violent extremist phenomena from a transnational perspective, rather than viewing incidents as single, isolated events.

21. Obaidi M, Bergh R, Akrami N, Anjum G: Group-based relative deprivation explains endorsement of extremism among western-born muslims. Psychol Sci 2019, 30:596-605

22. Obaidi M, Anjum G, Lindström J, Bergh R, Celebi E, Baykal M: The Role Muslim Identity in Predicting Violent Intentions to Defend Muslims. Group Processes and Intergroup relations; 2020. (in press).

23. Bal M, van den Bos K: From system acceptance to embracing alternative systems and system rejection: tipping points in processes of radicalization. Transl Issues Psychol Sci 2017, 3:241-253

24. van Zomeren M, Postmes $T$, Spears R: Toward an integrative social identity model of collective action: a quantitative research synthesis of three socio-psychological perspectives. Psychol Bull 2008, 134:504-535.

25. Jasko K, LaFree G, Kruglanski A: Quest for significance and violent extremism: the case of domestic radicalization. Political Psychol 2017, 38:815-831.

26. Jasko K, Webber D, Kruglanski AW, Gelfand M,

-• Taufiqurrohman M, Hettiarachchi M, Gunaratna R: Social context moderates the effects of quest for significance on violent extremism. Journal of Personality and Social Psychology Pers Soc Psychol 2019. online advance poublication.

26. Jasko K, Webber D, Kruglanski AW, Gelfand M, Taufiqurrohman M, Hettiarachchi M, Gunaratna R: Social context moderates the effects of quest for significance on violent extremism. Journal of Personality and Social Psychology 2019, online advance poublication.A quest for significance is known for predicting violent extremism. Across diverse, hard- to-reach samples and cultures, the authors showed that this relationship is moderated by the extent to which a social context is radical. Especially the role of quest for group-based significance was potentiated within such radical social contexts. This finding is important as it emphasizes the need to combine individual and contextual perspectives when understanding violent extremism.

27. Kruglanski AW, Chen X, Dechesne M, Fishman S, Orehek E: Fully committed: suicide bombers' motivation and the quest for personal significance. Political Psychol 2009, 30:331-357.

28. Moghaddam FM: The staircase to terrorism: a psychological exploration. Am Psychol 2005, 60:161-169.

29. van den Bos K: Unfairness and radicalization. Annu Rev Psychol 2020, 71:563-588

30. Kahn J, Weiner T: World Leaders Rethinking Strategy on Aid to Poor. The New York Times; 2002.

31. Tyson LDA: It's Time to Step Up the Global War on Poverty. Bloomberg Businessweek; 2001.

32. Atran S: Genesis of suicide terrorism. Science 2003, 299:15341539 .

33. Krueger $\mathrm{AB}$, Malečková J: Education, poverty and terrorism: is there a causal connection? J Econ Perspect 2003, 17:119-144.

34. Nivette A, Eisner M, Ribeaud D: Developmental predictors of violent extremist attitudes: a test of general strain theory. $J$ Res Crime Deling 2017, 54:755-790.

35. Alkhadher O, Scull NC: Demographic variables predicting ISIS and Daesh armed political violence. Crime Law Soc Change 2019, 72:183-194.

36. Haddad S: Accounting for Lebanese Muslims' perspectives on the Islamic state (ISIS): religious militancy, sectarianism and personal attributions. Def Secur Anal 2017, 33:242-262.

37. Bhui $\mathrm{K}$, Warfa N, Jones $\mathrm{E}$ : Is violent radicalisation associated with poverty, migration, poor self-reported health and common mental disorders? PLoS One 2014, 9 e90718-e90718.

38. Tahir H, Kunst JR, Sam DL: Threat, anti-western hostility and violence among European Muslims: the mediating role of acculturation. Int $J$ Intercult Relat 2019, 73:74-88.

39. van Bergen DD, Ersanilli EF, Pels TVM, De Ruyter DJ: TurkishDutch youths' attitude toward violence for defending the ingroup: what role does perceived parenting play? Peace Confl $\mathrm{J}$ Peace Psychol 2016, 22:120-133.

40. Korotayev AV, Shishkina AR: Relative Deprivation as a Factor of

- Sociopolitical Destabilization: Toward a Quantitative Comparative Analysis of the Arab Spring EventsCrossCultural Researchdeprivation as a factor of sociopolitical destabilization: toward a quantitative comparative analysis of the arab spring events. Cross Cult Res 2019 , 0:1069397119882364.

40. Korotayev AV, Shishkina AR: Relative Deprivation as a Factor of Sociopolitical Destabilization: Toward a Quantitative Comparative Analysis of the Arab Spring Events. Cross-Cultural Research 2019, $0: 1069397119882364$.This study tested whether relative deprivation, conceptualized as a decrease in population-level happiness over time, would predict highly-consequential, political events. Specifically, the authors found that, even when controlling for economic factors, a decrease in happiness from 2009 to 2010 prospectively predicted the extent to which countries experienced political destabilization during the Arab spring. The study is of importance as it shows how psychological changes and developments with regards to relative deprivation can predict future large-scale political events.

41. Doosje B, Loseman A, van den Bos K: Determinants of radicalization of islamic youth in the Netherlands: personal uncertainty, perceived injustice, and perceived group threat. $J$ Soc Issues 2013, 69:586-604.

42. van Bergen DD, Feddes AF, Doosje B, Pels TVM: Collective identity factors and the attitude toward violence in defense of ethnicity or religion among Muslim youth of Turkish and Moroccan descent. Int J Intercult Relat 2015, 47:89-100.

43. Henry PJ, Sidanius J, Levin S, Pratto F: Social dominance orientation, authoritarianism, and support for intergroup 
violence between the Middle East and America. Political Psychol 2005, 26:569-584.

44. Sidanius J, Kteily N, Levin S, Pratto F, Obaidi M: Support for asymmetric violence among Arab populations: the clash of cultures, social identity, or counterdominance? Group Process Intergroup Relat 2016, 19:343-359.

45. Kunst JR, Fischer R, Sidanius J, Thomsen L: Preferences for group dominance track and mediate the effects of macro-leve social inequality and violence across societies. Proc Natl Acad Sci U S A 2017, 114:5407-5412.

46. Sidanius J, Pratto F: Social Dominance: an Intergroup Theory of Social Hierarchy and Oppression. New York, US-NY: Cambridge University Press; 1999.

47. Osborne D, García-Sánchez E, Sibley CG: Identifying the psychological mechanisms underlying the effects of inequality on society: the macro-micro model of inequality and relative deprivation (MIRED). In The Social Psychology of Inequality. Edited by Jetten J, Peters K. Springer International Publishing; 2019:249-266.

48. Doosje B, van den Bos K, Loseman A, Feddes AR, Mann L: "My Ingroup is Superior!": susceptibility for radical right-wing attitudes and behaviors in Dutch youth. Negot Confl Manag Res 2012, 5:253-268.

49. Setiawan T, Scheepers P, Sterkens C: Applicability of the social identity model of collective action in predicting support for interreligious violence in Indonesia. Asian J Soc Psychol 2019. Online advance publication.

50. Kunst JR, Dovidio JF, Thomsen L: Fusion with political leaders

- predicts willingness to persecute immigrants and political opponents. Nature Human Behaviour Hum Behav 2019, 3:11801189.
50. Kunst JR, Dovidio JF, Thomsen L: Fusion with political leaders predicts willingness to persecute immigrants and political opponents. Nature Human Behaviour 2019, 3:11801189.This paper focused on how the relationship that partisans have with their leaders influences violent extremism. In one experiment, relative deprivation causally predicted more violent extremism targeted at out-groups. Importantly, this relationship was mediated by an increase in perceived closeness with the partisans' political leader. This finding is important as it highlights how relative deprivation may nurture leader cults that ultimately lead to intergroup violence.

51. Swann WB, Jetten J, Gómez Á, Whitehouse H, Bastian B: When group membership gets personal: a theory of identity fusion. Psychol Rev 2012, 119:441-456.

52. Morgan SL: Status threat, material interests, and the 2016 presidential vote. Socius 2018, 4:2378023118788217.

53. Pettigrew TF: Social psychological perspectives on trump supporters. J Soc Political Psychol 2017, 5:107-116.

54. Glasford DE: Seeing is believing: communication modality, anger, and support for action on behalf of out-groups. J Appl Soc Psychol 2013, 43:2223-2230.

55. Glasford DE, Pratto F: When extraordinary injustice leads to ordinary response: how perpetrator power and size of an injustice event affect bystander efficacy and collective action. Eur J Soc Psychol 2014, 44:590-601.

56. Bruneau E, Lane D, Saleem M: Giving the underdog a leg up: a counternarrative of nonviolent resistance improves sustained third-party support of a disempowered group. Soc Psychol Personal Sci 2017, 8:746-757.

57. Kunst JR, Boos B, Kimel SY, Obaidi M, Shani M, Thomsen L: Engaging in extreme activism in support of others' political struggles: the role of politically motivated fusion with outgroups. PLOS One 2018, 13:e0190639. 